\title{
Weathering Processes on Martian Craters: Implications on Recurring Slope Lineae and the Location of Liquid Water
}

\author{
Pablo Garcia-Chevesich ${ }^{1,2,3}$, Eduardo Bendek ${ }^{4}$, Roberto Pizarro ${ }^{5 *}$, Rodrigo Valdes-Pineda ${ }^{2}$, \\ David Gonzalez ${ }^{6}$, Horacio Bown², Eduardo Martínez², Luis Gonzalez ${ }^{2}$ \\ ${ }^{1}$ Department of Hydrology and Atmospheric Sciences \& Department of Agricultural and Biosystems Engineering, \\ University of Arizona, Tucson, USA \\ ${ }^{2}$ Faculty of Forest Sciences and Nature Conservation, International Hydrology Research Group, University of Chile, Santiago, Chile \\ ${ }^{3}$ International Sediment Initiative and International Hydrological Programme, UNESCO, Paris, France \\ ${ }^{4}$ Ames Research Center, NASA, Washington DC, USA \\ ${ }^{5}$ Technological Center for Environmental Hydrology, University of Talca, Talca, Chile \\ ${ }^{6}$ Faculty of Forest Sciences, University of Concepción, Concepción, Chile \\ Email: pablogarciach@gmail.com
}

How to cite this paper: Garcia-Chevesich, P., Bendek, E., Pizarro, R., Valdes-Pineda, R., Gonzalez, D., Bown, H., Martínez, E. and Gonzalez, L. (2017) Weathering Processes on Martian Craters: Implications on Recurring Slope Lineae and the Location of Liquid Water. Open Journal of Modern Hydrology, 7, 245-256.

https://doi.org/10.4236/ojmh.2017.74014

Received: November 10, 2016

Accepted: September 9, 2017

Published: September 12, 2017

Copyright (c) 2017 by authors and Scientific Research Publishing Inc. This work is licensed under the Creative Commons Attribution International License (CC BY 4.0).

http://creativecommons.org/licenses/by/4.0/ (c) (†) Open Access

\begin{abstract}
Recent attention has been put into recurring slope lineae (RSL), after the discovery that water is present in them. It is assumed that RSL are due to flowing water. However, even though that might be the case, the general characteristics of RSL as well as their seasonal and spatial distribution in Mars, and their occurrence within craters, suggest that RSL correspond to the weathering of frozen aquifers, which coincides with slope stability processes occurring in impact craters and scree slopes from Earth. In this study, we associated RSL with similar weathering processes occurring on impact craters and hydrogeological processes occurring on Earth (including ice, water, and wind erosion and natural aquifer recharge processes). We were able to create a conceptual model on how RSL develop, why are they found mostly in mid latitudes around craters, why are they present in more frequency in one side of crates in high latitudes, and why are there more RSL in the Martian southern hemisphere. Considering the whole hydrogeological processes occurring in craters that experience RSL, we were able to predict where large quantities of liquid water are most likely to be present in the red planet.
\end{abstract}

\section{Keywords}

Mars, Recurring Slope Lineae (RSL), Weathering Processes, Craters, Groundwater 


\section{Introduction}

For decades, mankind has been exploring our solar system with the hope of finding suitable conditions for life, as well as useful natural resources, among many other things. Furthermore, most attention has been placed on Mars, because of its similarity to Earth and the short astronomical distance between both planets. Despite the above, extra attention has gained the red planet after the recent discovery of hydrated salts in recurring slope lineae (RSL), an evidence that suggest the presence of liquid water flowing over the Martian surface [1]-[8]. Liquid water in Mars not only would help sustain life forms [9]; the vital element is also crucial for future human expeditions to our neighboring planet.

In fact, there is enough evidence to suggest that Mars was actually a planet with plenty of water, with rivers, lakes, and even oceans [10] [11]. Mars's current surface topography, characterized by the presence of countless rills, gullies, and channels, is a clear indication of some types of fluid (most likely water) eroding the surface of the planet, a condition that occurred billions of years ago [12] [13]. Many studies support the existence of liquid water flowing in Mars in the past. For example, based on water-derived erosion formations in tectonic faults, Treiman [14] suggested that liquid groundwater near the Martian surface was present about 3500 - $1800 \mathrm{Myr}$ ago. Similarly, Williams et al. [13] developed a model that provided a simple explanation for the latitudinal distribution of Martian gullies, suggesting that the gullies were formed when water migrated away from the present poles to the mid-latitudes.

Thus, almost four billion years ago the planet lost most of its liquid water and atmosphere due to solar winds [15] [16]. It is believed that only "modest atmospheric loss" has occurred ever since and that the Martian atmosphere's water content hasn't changed much for the last 165 million years [17]. In addition, not having an atmosphere means extremely low temperatures, i.e. everything that was exposed to the planet's thin atmosphere froze, including crater and canyon walls [18].

As for the presence of liquid water in current days, besides the RSL reports previously mentioned, recent research suggests that there might be thin liquid water layers in the surface of the planet in present times, after condensation and for short periods [19] Moreover, Kereszturi and Appéré [20] suggested that "good chance exists for the presence of liquid interfacial water in the warmest part of the day in the northern hemisphere of Mars at extended areas-although firm evidence requires better targeted future observations".

Despite the above, and most likely not associated with flowing water, erosion and sedimentation processes continue to be active in Mars [21]-[28], though it has been suggested that gully formation is not necessarily restricted to a single hydrological process [29]. Moreover, erosion processes in Mars are strictly associated with gravity erosion and, according to recent RSL foundlings, with short periods of liquid water flows [2].

It is now known that RSL are concentrated in equatorial latitudes, with higher occurrences in the southern hemisphere of the planet, and being relatively ab- 
sent, with less numbers within craters, and with smaller dimensions in northern latitudes [2] [3] [30]. Additionally, RSL occur mostly during summer months, being higher in number in north-facing slopes of craters located in southern latitudes and in south-facing slopes on craters from the northern hemisphere. Also, equatorial craters have a relatively homogeneous distribution of RSL along their circumference, or slopes, suggesting all together that they are correlated with sun exposure [3]. In other words, RSL have a tendency to occur on the most unstable slopes of Martian craters, i.e. those receiving more direct sunrays during summers. Typically, one would expect the more stable slopes of a crater to have more vertical slopes (since they are not as affected by weathering processes as the slopes located in front of them). Thus, this study focuses on the relationship between RSL and latitudinal slope stability distribution within Martian craters, as related to terrestrial impact craters' latitudinal slope stability. Additionally, based on natural aquifer recharge processes occurring on Earth, we developed a conceptual model indicating where liquid water might be abundant in the red planet, based on the presence of RSL.

\section{Research Methods}

Based on Google Earth images and slope profile applications, we evaluated Earth's slope stability within impact craters at different latitudes. Thus, we evaluated slope stability based on visual characteristics and elevation profiles, comparing north and south slopes within each crater. We compared terrestrial slope stability tendencies with RSL locations within craters and latitudes on Mars. Our intention was to find out whether RSL might be related to Mars' rock weathering processes (i.e. slope stability), following the findings by McEwen et al. [7], with the purpose of searching a possible explanation for their appearance and their geographical distribution within craters at different latitudes.

Additionally, we analyzed current knowledge on Mars's orbit around the sun, specifically its eccentricity, to see if that could explain why RSL are less abundant in the northern hemisphere, that is if they are actually related to rock weathering processes.

Finally, after finding the above relationships and assuming that RSL correspond to a weathering process occurring mostly on slopes that experience more sun exposure during Martian summers, we followed similar Earth's natural water cycles and created a simple conceptual hydrological model, leading us to where liquid water might be abundant in the red planet.

\section{Results and Discussion}

Unfortunately, just a few terrestrial impact craters were intact enough to see differences between north and south slopes; many craters simply have too much vegetation, human constructions, or wind-driven sand deposits to be able to evaluate slope stability differences just based on areal views and digital north-to-south elevation profile transects. The relationship between slope stability within qualified impact craters and their general location on Earth is shown in Table 1. 
Table 1. Location of some impact craters on Earth and spatial distribution of their more unstable slopes around them.

\begin{tabular}{ccc}
\hline Impact crater's name and location & Hemisphere & Location of more unstable slope \\
\hline Amguid, Algeria & Equatorial & No visible differences \\
Aorounga, Chad & Equatorial & No visible differences \\
Aouelloul, Mauritania & Equatorial & No visible differences \\
Bosumtwi, Ghana & Equatorial & No visible differences \\
Lonar, India & Equatorial & No visible differences \\
Meteor, Arizona & Northern & North \\
Monturaqui, Chile & Southern & South \\
Roter Kamm, Namibia & Southern & South \\
Tenoumer, Mauritania & Equatorial & No visible differences \\
Tswaing, South Africa & Southern & South \\
Vredefort, South Africa & Southern & South \\
Wolfe Creek, Australia & Southern & South \\
\hline
\end{tabular}

Considering the 12 qualified terrestrial impact craters found, there is a clear tendency to have more differences in slope stability on craters located in higher latitudes.

As shown in Table 1, terrestrial craters located in northern latitudes have a clear tendency to be gentler (i.e. more geologically unstable) in the north portion of the crater's circumference (i.e. the south-facing slopes). In southern latitudes, on the other hand, the south slopes (or north-facing slopes) of craters are usually more unstable, compared to slopes located in the north side. Additionally, craters located near our planet's equator tend to show no differences in slope stability around their edges. According to our results, this latitudinal effect on crater's slope stability distribution tends to be clearer on craters located in desert areas of our planet, where none or little plant protection exists since none or little rainfall occurs, and where temperature oscillations are broader. Finally, the most reasonable explanation for these differences in slope stability within craters is the angle in which sunrays heat the slopes of the craters. Thus, craters located in the northern hemisphere (e.g. Meteor Crater in Arizona, Figure 1, left) receive more direct sunrays during summers in their south-facing slopes, whereas the opposite happens in craters at the southern hemisphere (e.g. Monturaqui Crater in Chile, Figure 1, center). Additionally, craters near the equator receive sunrays at similar angles, all year round (e.g. Tenoumer Crater in Mauritania, Figure 1, right).

Coincidentally, RSL follow similar latitudinal slope distributions than that from terrestrial craters' stability [2] [31] [32], which is an indication that such phenomenon is probably part of a weathering process in the red planet [7]. The occurrence of RSL in Mars is stronger in craters' slopes receiving more direct sunrays, as previously mentioned [2] [3]. 


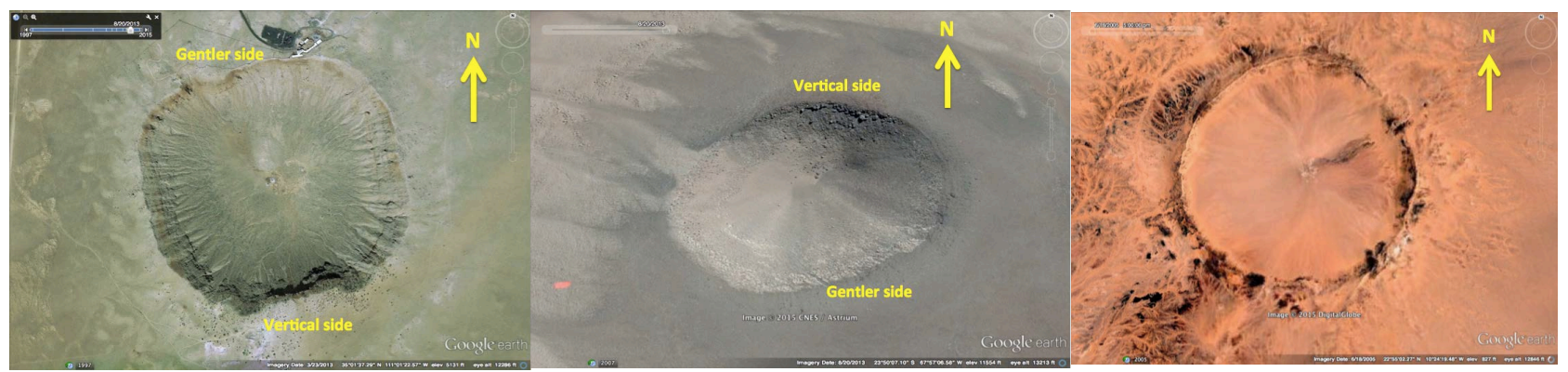

Figure 1. Left: Meteor Crater in Arizona (northern hemisphere, Northern Arizona desert), an example of the effects of latitude on the spatial distribution of a crater's geological slope stability. As one can see, the most unstable slopes are located in the northern side of the crater, whereas the southern slopes are more vertical. Center: Monturaqui Crater, Chile (southern hemisphere, Atacama Desert), where more unstable slopes are located in the southern portion of the crater's edges. Right: Tenoumer Crater located in Mauritania (Equatorial latitude, Saharan desert), showing no differences on slope stability around the crater. Source: Google Earth.

Recent discoveries indicate that RSL contain significant amounts of hydrated salts [2] [31] [32], suggesting that such dark pathways might be the reminding of a frozen aquifer [5]. Even though the presence of fluid water in RSL has been confirmed [2], it is unclear whether RSL move downslope under fluid conditions. It is known that RSL move downslope by gravity, on a relatively viscous way, and in a relatively concentrated form [3] (Figure 2). However, liquid flows on Earth, more specifically liquid debris flows (which is the most similar liquid process associated with rock weathering on steep rocks similar to Martian craters) get more concentrated as the flow travels down the slope, ending up in a semi-circular, tongue-shaped form [33], not being the case for RSL, in which the bottom ends get wider and in different directions, a behavior associated with dry rock flows on Earth, or "scree avalanches", which are loose rock sliding down the slope as they break apart by the action of gravity, weathering processes, and occasional liquid flows, as shown in Figure 3 [34]. Scree slopes are characteristic of Andean or Alpine rock weathering processes on steep slopes, among other sites on Earth [35] [36] [37], similar to those experiencing RSL in Mars [7].

The absence of liquid following water on RSL was also confirmed by Edwards and Piqueux [38], who analyzed temperature data and a numerical heat transfer model. Similarly, Heinz et al. [39] concluded that RSL might not be associated with flowing liquid water, suggesting that their association with gullies may be the result of ancient flowing water.

In addition to the above, RSL material's downslope traveling speed has been estimated to be between $5.8 \times 10^{-7}$ and $3.2 \times 10^{-5} \mathrm{~m} / \mathrm{s}$ [40], being that too slow to be attributed to permanent liquid water in such steep slopes, though consideration must be taken into the lower gravitational forces on Mars' surface, compared to our planet [41]. However, Mangold et al. [42] documented RSL velocities of 1 - $7 \mathrm{~m} / \mathrm{s}$, suggesting that the moving mass should carry between 10 and $40 \%$ of liquid water. Moreover, based on available RSL images, no rills or gullies are formed when this interesting phenomenon occurs, also an indication that no 


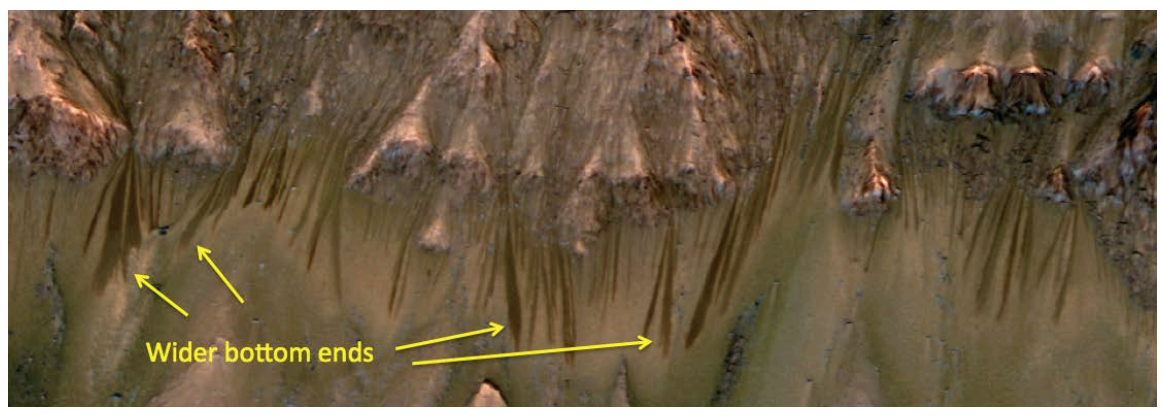

Figure 2. Wider bottoms are an indication that gravity might be the main factor for the transportation of RSL downslope. Image taken by the Mars Reconnaissance Orbiter. NASA/JPL/University of Arizona.

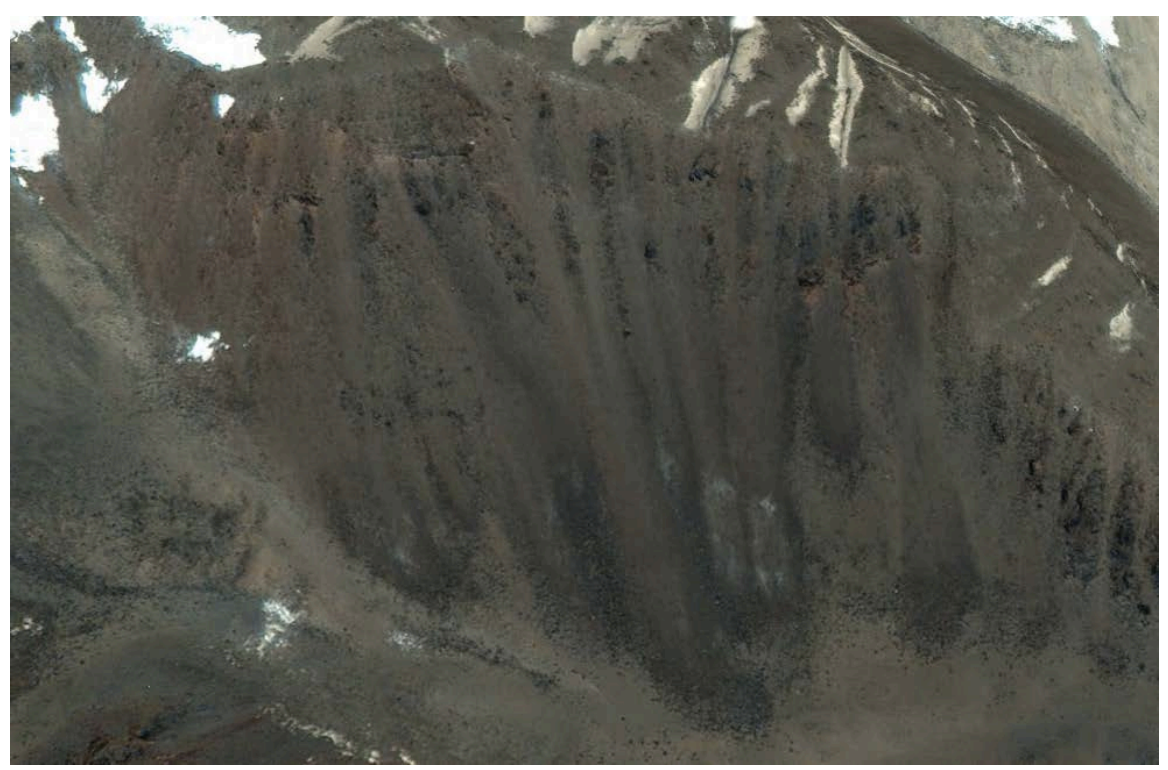

Figure 3. Dry rock flows at an unstable slope in north-facing slopes of Chilean Andes. The flows follow similar paths as those from RSL in Mars. Source: Google Earth.

liquid water is flowing down the slope. As a consequence, in order to better understand RSL in Mars, it is strictly necessary to study scree slope processes on Earth.

The above suggests that RSL might be some form of solid rock material that travels downslope by both, gravity and intermittent fluid water during summer days, when surface temperatures can reach $20^{\circ} \mathrm{C}$ [43] and melting of the water contained in the broken, frozen geologic material can flow down the slope, eroding the remaining material for short distances ("material" refers to either frozen sediments or frozen rocks, a currently unknown composition). This agrees the finding by Ojha et al. [2], since liquid water is likely to be present on the crater's slopes; however, based on the geomorphological characteristics of scree slopes (mostly rocks and gravels), one could expect that most of the melted water infiltrates into the coarse media located underneath [32], rather than flowing down the slope. 
Thus, RSL are able to travel so far down with most of their liquid water being infiltrated into the ground, as it occurs with scree slopes on Earth, by the action of gravity, as the material breaks down, probably on a daily base [44] [45] [46]. Since the darker material (RSL) is apparently the one that degrades at the fastest rates within the crater's rock walls, it is an indication that water might be involved in the form of, for example, frozen, saturated sediments or rocks, as previously mentioned.

Mars is a cold planet with a dry atmosphere [18] [43] in which physical weathering occurs at much higher rates, as a result of its extremely cold temperatures, and wide temperature oscillations during summers, when compared to planet Earth [29]. Thus, the constant freezing and thawing occurring between day and night on the Martian surface during summers is probably enough to quickly break down the remaining RSL material. As summer goes on, RSL material continues to be broken apart into smaller pieces, after being exposed to nearly $100^{\circ} \mathrm{C}$ temperature oscillations [43], a difference that can be reached only during summers, which explains the seasonal occurrence of RSL reported by McEwen et al. [7]. Eventually, the RSL material most likely releases all of its water contents, since all of their water was either evaporated or melted. The process repeats itself until the frozen rocks are likely to be reduced into smaller and smaller pieces, ending up in small, dry sediment particles, which are probably either eroded by the Martian winds [47], buried by wind-driven sediments being carried from elsewhere, as it occurs in scree slopes on high mountains of Iceland [48], or the material is simply oxidized, a common process on Martian surface, which is the responsible for the planet's characteristic red color [49]. Despite the above, the reason why RSL vanish by the end of summers continues to be unknown and more research is needed to find out what is really happening.

The existence of those saturated, frozen materials (aquifers) is supported by the findings of Kurokawa et al. [50] and Chen et al. [51], among others, who suggested that significant amounts of underground water/ice should exist at present days in Mars. In addition, since RSL contain water [2], future attention should be taken to find out how much of the frozen water contained in RSL actually melt, drain, and percolate into the ground underneath, at the crater's piedmonts, most likely resulting in aquifer recharge with liquid water [52], as it happens in similar conditions on Earth [53]. Even if a small portion of the ice-melted water contained in the RSL material is able to infiltrate into the media located below it, it is an indication of the existence of abundant liquid groundwater under the crater's surface. Thus, melted RSL percolated water is likely to remain freeze-free thanks to the great insulating properties of the soil layers located above the water table, just like occurs in cold regions of our planet [54].

Finally, as previously mentioned, RSL episodes are larger in quantity in the southern hemisphere compared to those occurring in northern latitudes. Such differences are probably a result of Mars's trajectory around the sun. As the red planet follows its trajectory around our star, its hemispheres get exposed to solar radiation at different angles (i.e. winter and summer). However, just like on 
Earth and Milankovic's theory about the relationship between solar radiation and eccentricity [55], one of the main responsible factors for terrestrial ice ages, Mars has the highest orbital eccentricity of any planet within our solar system [56] [57], resulting in summers with less solar radiation in the northern hemisphere, i.e. less RSL. With this information we can now suggest that, considering the highly eccentric orbit of Mars, the southern hemisphere is where more aquifer recharge might be occurring on craters experiencing RSL.

\section{Conclusions and Recommendations}

Based on all the above, we suggest that RSL are part of weathering processes, similar to those occurring on Earth's impact craters and on Andean and Alpine scree slopes, in which the constant freezing and thawing of frozen rocks during Martian summer nights and days, respectively, quickly break down the material, releasing its water through melting and evaporation processes. We are well aware that Earth and Mars cannot be compared directly; vegetation and gravitational forces make the above comparisons somewhat uncertain. Nevertheless, we believe the processes, and not the magnitudes, to be the same.

Based on RSL hydrologic characteristics, it is most likely that liquid water is produced during summer days, agreeing with the finding by Ojha et al. [2], when temperatures can reach $20^{\circ} \mathrm{C}$ and day-night oscillations are nearly $100^{\circ} \mathrm{C}$. However, based on terrestrial hydrological processes occurring in similar conditions, it is possible that such liquid water percolates into the ground below the RSL, rather than flowing downslope. Moreover, we conclude that in order to better understand RSL processes, it is strictly necessary to study scree slope processes occurring on upland Andes and Alps.

The above conclusion suggests that abundant liquid water is likely to exist in the form of groundwater underneath craters experiencing RSL, as melted water produced during this fascinating hydrological process recharges the crater's aquifer.

Based on our perspectives, future research should focus on answering questions like 1) How much of the RSL's liquid water infiltrate into the ground below it? 2) What is the textural composition of the piedmonts over which RSL moves over? 3) Are there aquifers with liquid water below the craters experiencing RSL? 4) What is the composition of RSL material: frozen sediments or frozen rocks with high water contents?

In addition to the above, since probabilities for finding living organisms in Mars are strictly associated with liquid water, life is likely to be located beneath craters, where sufficient soil layers protect the ice-melted RSL percolated water from freezing, as it occurs on cold regions of Earth.

\section{References}

[1] Chojnacky, M., McEwen, A., Dundas, C., Ojha, L., Urso, A. and Sutton, S. (2016) Geologic Context of Recurring Slope Lineae in Melas and Coprates Chasmata, 
Mars. Journal of Geophysical Research, Planets, 121, 1204-1231. https://doi.org/10.1002/2015JE004991

[2] Ojha, L., Wilhelm, M.B., Murchie, S.L., McEwen, A.S., Wray, J.J., Hanley, J., Massé, M. and Chojnacki, M. (2015) Spectral Evidence for Hydrated Salts in Recurring Slope Lineae on Mars. Nature Geosciences, 8, 829-832. https://doi.org/10.1038/ngeo2546

[3] McEwen, A.S., Dundas, C.M., Mattson, S.S., Toigo, A.D., Ojha, L., Wray, J.J., Chojnacki, M., Byrne, S., Murchie, S.L. and Thomas, N. (2014) Recurring Slope Lineae in Equatorial Regions of Mars. Nature Geosciences, 7, 53-58. https://doi.org/10.1038/ngeo2014

[4] Ojha, L., McEwen, A., Dundas, C., Byrne, S., Mattson, S., Wray, J., Masse, M. and Schaefer, E. (2014) HiRISE Observations of Recurring Slope Lineae (RSL) during Southern Summer on Mars. Icarus, 231, 365-376. https://doi.org/10.1016/j.icarus.2013.12.021

[5] Stillman, D.E., Michaels, T.I., Grimm, R.E. and Harrison, K.P. (2014) New Observations of Martian Southern Mid-Latitude Recurring Slope Lineae (RSL) Imply Formation by Freshwater Subsurface Flows. Icarus, 233, 328-341. https://doi.org/10.1016/j.icarus.2014.01.017

[6] Chevrier, V.F. and Rivera-Valentin, E.G. (2012) Formation of Recurring Slope Lineae by Liquid Brines on Present-Day Mars. Geophysical Research Letters, 39, L21202. https://doi.org/10.1029/2012GL054119

[7] McEwen, A.S., Ojha, L., Dundas, C.M., Mattson, S.S., Byrne, S., Wray, J.J., Cull, S.C., Murchie, S.L., Thomas, N. and Gulick, V.C. (2011) Seasonal Flows on Warm Martian Slopes. Science, 333, 740-743. https://doi.org/10.1126/science.1204816

[8] Lanza, N.L., Meyer, G.A., Okubo, C.H., Newsom, H.E. and Wiens, R.C. (2010) Evidence for Debris Flow Gully Formation Initiated by Shallow Subsurface Water on Mars. Icarus, 205, 103-112. https://doi.org/10.1016/j.icarus.2009.04.014

[9] Bamsey, M., Berinstain, A., Auclair, S., Battler, M., Binsted, K., Bywaters, K., Harris, J., Kobrick, R. and McKay, C. (2009) Four-Month Moon and Mars Crew Water Utilization Study Conducted at the Flashline Mars Arctic Research Station, Devon Island, Nunavut. Advances in Space Research, 43, 1256-1274.

https://doi.org/10.1016/j.asr.2009.01.009

[10] Di Achille, G. and Hynek, B.M. (2010) Ancient Ocean on Mars Supported by Global Distribution of Deltas and Valleys. Nature Geosciences, 3, 459-463. https://doi.org/10.1038/ngeo891

[11] McCubbin, F.M., Smirnov, A., Nekvasil, H., Wang, J., Hauri, E. and Lindsley, D.H. (2010) Hydrous Magmatism on Mars: A Source of Water for the Surface and Subsurface during the Amazonian. Earth and Planetary Science Letters, 292, 132-138.

[12] Dickson, J.L. and Head, J.W. (2009) The Formation and Evolution of Youthful Gullies on Mars: Gullies as the Late-Stage Phase of Mars' Most Recent Ice Age. Icarus, 204, 63-86.

[13] Williams, K.E., Toon, O.B., Heldmann, J.L. and Mellon, M.T. (2009) Ancient Melting of Mid-Latitude Snowpacks on Mars as a Water Source for Gullies. Icarus, 200, 418-425.

[14] Treiman, A.H. (2008) Ancient Groundwater Flow in the Valles Marineris on Mars Inferred from Fault Trace Ridges. Nature Geosciences, 1, 181-183. https://doi.org/10.1038/ngeo131

[15] Lundin, R. and Barabash, S. (2004) Evolution of the Martian Atmosphere and Hy- 
drosphere: Solar Wind Erosion Studied by ASPERA-3 on Mars Express. Planetary and Space Science, 52, 1059-1071.

[16] Perez-De-Tejada, H. (1992) Solar Wind Erosion of the Mars Early Atmosphere. Journal of Geophysical Research, 97, 3159-3167. https://doi.org/10.1029/91JA01985

[17] Greenwood, J.P., Itoh, S., Sakamoto, N., Vicenzi, E.P. and Yurimoto, H. (2008) Hydrogen Isotope Evidence for Loss of Water from Mars through Time. Geophysical Research Letters, 35, L05203. https://doi.org/10.1029/2007GL032721

[18] Mahaffy, P.R., Webster, C.R., Stern, J.C., Brunner, A.E., Atreya, S.K., Conrad, P.G., Domagal-Goldman, S., Eigenbrode, J.L., Flesch, G.J., Christensen, L.E., Franz, H.B., Freissinet, C., Glavin, D.P., Grotzinger, J.P., Jones, J.H., Leshin, L.A., Malespin, C., McAdam, A.C., Ming, D.W., Navarro-Gonzalez, R., Niles, P.B., Owen, T., Pavlov, A.A., Steele, A., Trainer, M.G., Williford, K.H., Wray, J.J. and the MSL Science Team (2014) Mars Atmosphere-The Imprint of Atmospheric Evolution in the D/H of Hesperian Clay Minerals on Mars. Science, 347, 412-414.

[19] Kereszturi, A. and Rivera-Valentin, E.G. (2012) Locations of Thin Liquid Water Layers on Present-Day Mars. Icarus, 221, 289-295.

[20] Kereszturi, A. and Appéré, T. (2014) Searching for Springtime Zonal Liquid Interfacial Water on Mars. Icarus, 238, 66-76.

[21] Watkins, J.A., Ehlmann, B.L. and Yin, A. (2015) Long-Runout Landslides and the Long-Lasting Effects of Early Water Activity on Mars. Geology, 43, 107-110. https://doi.org/10.1130/G36215.1

[22] Dundas, C.M. and McEwen, A.S. (2015) Slope Activity in Gale Crater, Mars. Icarus, 254, 213-218.

[23] Thomas, P.C., Calvin, W.M., Gierasch, P., Haberle, R., James, P.B. and Sholes, S. (2013) Time Scales of Erosion and Deposition Recorded in the Residual South Polar Cap of Mars. Icarus, 225, 923-932.

[24] Hansen, C.J., Bourke, M., Bridges, N.T., Byrne, S., Colon, C., Diniega, S., Dundas, C., Herkenhoff, K., McEwen, A., Mellon, M., Portyankina, G. and Thomas, N. (2011) Seasonal Erosion and Restoration of Mars' Northern Polar Dunes. Science, 331, 575-578. https://doi.org/10.1126/science.1197636

[25] Golombek, M.P., Grant, J.A., Crumpler, L.S., Greeley, R., Arvidson, R.E., Bell III, J.F., Weitz, C.M., Sullivan, R., Christensen, P.R., Soderblom, L.A. and Squyres, S.W. (2006) Erosion Rates at the Mars Exploration Rover Landing Sites and Long-Term Climate Change on Mars. Journal of Geophysical Research D, Atmospheres, 111, E12. https://doi.org/10.1029/2006JE002754

[26] Neuffer, D.P. and Schultz, R.A. (2006) Mechanisms of Slope Failure in Valles Marineris, Mars. Quarterly Journal of Engineering Geology and Hydrogeology, 39, 227-240. https://doi.org/10.1144/1470-9236/05-042

[27] Musselwhite, D.S., Swindle, T.D. and Lunine, J.I. (2001) Liquid CO2 Breakout and the Formation of Recent Small Gullies on Mars. Geophysical Research Letters, 28, 1283-1286. https://doi.org/10.1029/2000GL012496

[28] Golombek, M.P. and Bridges, N.T. (2000) Erosion Rates on Mars and Implications for Climate Change: Constraints from the Pathfinder Landing Site. Journal of Geophysical Research, 105, 1841-1853. https://doi.org/10.1029/1999JE001043

[29] Hobbs, S.W., Paull, D.J. and Clarke, J.D.A. (2014) A Comparison of Semiarid and Subhumid Terrestrial Gullies with Gullies on Mars: Implications for Martian Gully Erosion. Geomorphology, 204, 344-365.

[30] Dundas, C.M., McEwen, A.S. and Sutton, S. (2015) New Constraints on the Loca- 
tions, Timing, and Conditions for Recurring Slope Lineae Activity on Mars. Proceedings of the 46th Lunar and Planetary Science Conference, The Woodlands, 16-20 March 2015.

[31] Martín-Torres, F.J., Zorzano, M.P., Valentín-Serrano, P., Harri, A., Genzer, M., Kemppinen, O., Rivera-Valentin, E.G., Jun, I., Wray, J., Madsen, M.B., Goetz, W., McEwen, A.S., Hardgrove, C., Renno, N., Chevrier, V.F., Mischna, M., Navarro-González, R., Martínez-Frías, J., Conrad, P., McConnochie, T., Cockell, C., Berger, G., Vasavada, A.R., Sumner, D. and Vaniman, D. (2015) Transient Liquid Water and Water Activity at Gale Crater on Mars. Nature Geosciences, 8, 357-361. https://doi.org/10.1038/ngeo2412

[32] Grimm, R.E., Harrison, K.P. and Stillman, D.E. (2014) Water Budgets of Martian Recurring Slope Lineae. Icarus, 233, 316-327.

[33] Baratoux, D., Mangold, N., Delacourt, C. and Allemand, P. (2002) Evidence of Liquid Water in Recent Debris Avalanche on Mars. Geophysical Research Letters, 29, $1-4$.

[34] Hungr, O. (1995) A Model for the Runout Analysis of Rapid Flow Slides, Debris Flow, and Avalanches. Canadian Geotechnical Journal, 32, 610-623. https://doi.org/10.1139/t95-063

[35] Bithell, M., Richards, K.S. and Bithell, E.G. (2014) Simulation of Scree-Slope Dynamics: Investigating the Distribution of Debris Avalanche Events in an Idealized Two-Dimensional Model. Earth Surface Processes and Landforms, 39, 1601-1610.

[36] McGuire, A. and Pelletier, J.D. (2013) Relationships between Debris Fan Morphology and Flow Rheology for Wet and Dry Flows on Earth and Mars: A Numerical Modeling Investigation. Geomorphology, 197, 145-155.

[37] Hales, T.C. and Roering, J.J. (2005) Climate-Controlled Variations in Scree Production, Southern Alps, New Zealand. Geology, 33, 701-704.

https://doi.org/10.1130/G21528.1

[38] Edwards, C.S. and Piqueaux, S. (2016) The Water Content of Recurring Slope Lineae on Mars. Geophysical Research Letters, 43, 8912-8919. https://doi.org/10.1002/2016GL070179

[39] Heinz, J., Schulze-Macuch, D. and Kounaves, S.P. (2016) Deliquescence-Induced Wetting and RSL-Like Darkening of a Mars Analogue Soil Containing Various Perchlorate and Chloride Salts. Geophysical Research Letters, 43, 4880-4884. https://doi.org/10.1002/2016GL068919

[40] Levy, J. (2012) Hydrological Characteristics of Recurrent Slope Lineae on Mars: Evidence for Liquid Flow through Regolith and Comparisons with Antarctic Terrestrial Analogs. Icarus, 219, 1-4.

[41] Smith, D.E., Zuber, M.T., Torrence, M.H., Neumann, G.A., Lemoine, F.G. and Fricke, S.K. (2009) Time Variations of Mars' Gravitational Field and Seasonal Changes in the Masses of the Polar Ice Caps. Journal of Geophysical Research, 114, E05002. https://doi.org/10.1029/2008JE003267

[42] Mangold, M., Costard, F. and Forget, F. (2003) Debris Flows over Sand Dunes on Mars: Evidence for Liquid Water. Journal of Geophysical Research, 8, 5027. https://doi.org/10.1029/2002JE001958

[43] Sprague, A.L., Hunten, D.M., Doose, L.R. and Hill, R.E. (2003) Mars Atmospheric Water Vapor Abundance: 1996-1997. Icarus, 163, 88-101.

[44] Sass, O. and Krautblatter, M. (2007) Debris Flow-Dominated and Rockfall-Dominated Talus Slopes: Genetic Models Derived from GPR Measurements. Geomorphology, 
86, 176-192.

[45] Nyssen, J., Poesen, J., Moeyersons, J., Deckers, J. and Haile, M. (2006) Processes and Rates of Rock Fragment Displacement on Cliffs and Scree Slopes in an Amba Landscape, Ethiopia. Geomorphology, 81, 265-275.

[46] Blijenberg, H.M. (1995) In Situ Strength Tests of Coarse, Cohesionless Debris on Scree Slopes. Engineering Geology, 39, 137-146.

[47] Bishop, M.A. (2011) Aeolian Scours as Putative Signatures of Wind Erosion and Sediment Transport Direction on Mars. Geomorphology, 125, 569-574.

[48] De Vet, S.J. and Cammeraat, E.L.H. (2012) Aeolian Contributions to the Development of Hillslopes and Scree Sediments in Grænagil, Torfajökull, Iceland. Geomorphology, 175-176, 74-85.

[49] Zalutskii, A.A., Zalutskaya, A.A., Sed'mov, N.A. and Kuz'min, R.N. (2015) The Mössbauer Analysis of Iron Oxyhydroxides in Soils of Earth and Mars. Permafrost and Periglacial Processes, 18, 301-308. https://doi.org/10.1134/S0024490215040069

[50] Kurokawa, H., Sato, M., Ushioda, M., Matsuyama, T., Moriwaki, R., Dohm, J.M. and Usui, T. (2014) Evolution of Water Reservoirs on Mars: Constraints from Hydrogen Isotopes in Martian Meteorites. Earth and Planetary Science Letters, 394, 179-185.

[51] Chen, Y., Liu, Y., Guan, Y., Eiler, J.M., Ma, C., Rossman, G.R. and Taylor, L.A. (2015) Evidence in Tissint for Recent Subsurface Water on Mars. Earth and Planetary Science Letters, 425, 55-63.

[52] Hecht, M.A. (2002) Metastability of Liquid Water on Mars. Icarus, 156, 373-386.

[53] Zhai, Y., Wang, J., Teng, Y. and Zuo, R. (2011) Hydrogeochemical and Isotopic Evidence of Groundwater Evolution and Recharge in Aquifers in Beijing Plain, China. Environmental Earth Sciences, 69, 2167-2177.

https://doi.org/10.1007/s12665-012-2045-9

[54] Lei, S., Daniels, J.L., Bian, Z. and Wainaina, N. (2011) Improved Soil Temperature Modeling. Environmental Earth Sciences, 62, 1123-1130. https://doi.org/10.1007/s12665-010-0600-9

[55] Wieczorek, U. (2010) Milankovic's Theory: Multidimensional Visualisation of the Change of Insolation and Indicators of Climatic Change from 100000 before Present to 100000 after Present (in Intervals of 1,000 Years). International Journal of Earth Sciences, 99, 201-205. https://doi.org/10.1007/s00531-008-0377-1

[56] Huang, Z. and Cheng-Li, H. (2015) Sensitivity Study of High Eccentricity Orbits for Mars Gravity Recovery. Research in Astronomy and Astrophysics, 10, 107-116.

[57] He, Z. and Huang, C. (2015) Sensitivity Study of High Eccentricity Orbits for Mars Gravity Recovery. Research in Astronomy and Astrophysics, 15, 107-116. https://doi.org/10.1088/1674-4527/15/1/010 